\title{
Understanding the Political Economy of the Adaptation Fund
}

\author{
Sven Harmeling and Alpha O. Kaloga*
}

\begin{abstract}
The Adaptation Fund has become a fully operational institution for international adaptation finance. We explore different aspects of political economy, addressing the international institutional competition which influenced the decision on operating modalities in the $2007 \mathrm{UN}$ climate negotiations in Bali and which continues to be important for the future of the Fund in international climate finance. From the Adaptation Fund Board (AFB), the governing body of the Fund, this article examines the implications of interests represented by AFB members for key issues such as the prioritisation of countries and decisions on specific projects and programmes. Finally, power relationships around the concrete implementation of projects in developing countries are analysed. While the early stage of the Fund only allows for preliminary conclusions, the article points to some measures the AFB can undertake to address the challenges identified.
\end{abstract}

\begin{abstract}
1 Introduction
The Adaptation Fund was established under the Kyoto Protocol to assist vulnerable developing countries in the implementation of concrete adaptation projects and programmes. The Fund was originally agreed during the 7 th Conference of the Parties (COP7) to the UN Framework Convention on Glimate Change (UNFCGG) held in Marrakesh, Morocco, in 2001, but it wasn't until 2007 at COP13 that the Adaptation Fund Board (AFB) was established to design and govern the Fund. In 2010, the Fund became fully operational for financing implementation of adaptation initiatives and is now an institution with a particular role in the international climate finance arena.
\end{abstract}

Table 1 gives an overview of the total revenues of the organisation and the key projects funded per country. Its particular features make the Fund stand out from other climate change financing mechanisms: it operates under the authority of the UNFGCG country Parties at COP; there is opportunity for direct access of funds rather than through a UN implementing agency; the governance structure has a majority of developing country representatives; the levy on the trading of carbon credits (Certified Emission Reductions (CERs)) under the Clean Development Mechanism (CDM) provides an innovative funding source; and it has the strategic priority to give special attention to most vulnerable communities (Chandani et al. 2009).

Understanding the political economy of climate change as processes by which ideas, power and resources are conceptualised, negotiated and implemented at different scales in climate change initiatives, this article examines three different aspects of political economy of the Fund:

- The role of the Fund in the international policy arena, including power relationships with other institutions such as the Global Environment Facility (GEF) or the World Bank;

- Governance in the AFB, including the role of its members' interests in specific decisionmaking;

- Inclusiveness and distribution of responsibilities regarding project implementation by developing countries.

This article argues that the political economy of the Fund has been of vital importance since its establishment, and as it begins to implement projects, the more levels of powers and interests of certain stakeholders are apparent. This holds for the international institutional competition, as 


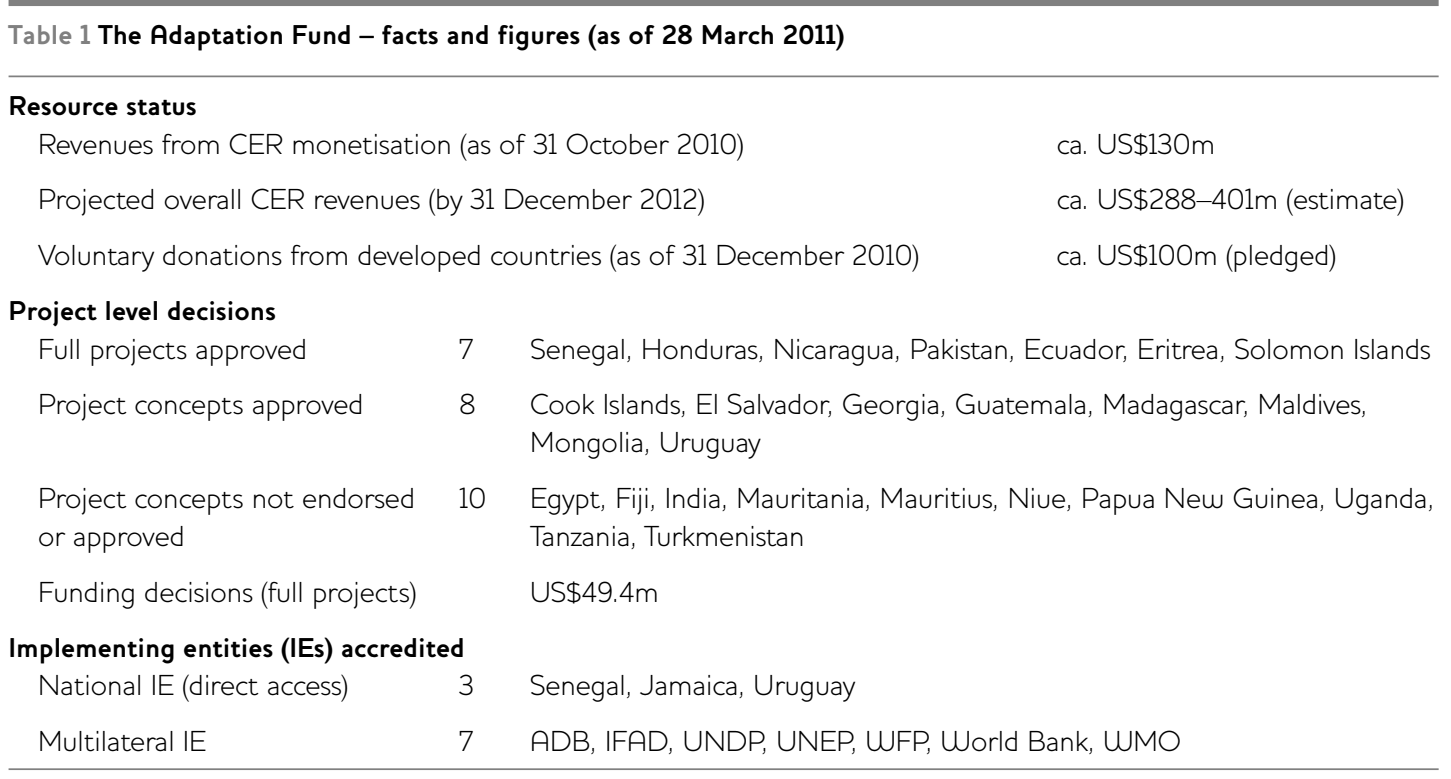

Source Own compilation, based on Germanwatch (2010).

well as for the implementation within developing countries, where the relationship between governments and non-governmental stakeholders are crucial.

While it is too early to draw conclusions regarding the implementation of the Fund, highlighting relevant issues at this early stage can help identify benchmarks against which future development of it can be measured. Our analysis demonstrates that it is important for the AFB to actively address political economy aspects. Potentially useful measures include a greater transparency on the project and programme decisions and clearer guidelines for governments to include non-governmental stakeholders in the project cycle.

\section{Political economy at the international level: origins and the future of the Fund}

After some progress had been reached at the climate summit held in 2006 in Nairobi (see Müller 2006), the following year's UNFCGC summit in Bali resulted in a breakthrough decision, which allowed the AFB to start its work. However, this decision could only be achieved after considerable controversy. The Bali meeting agreed to set up the Adaptation Fund under the authority of the COP (the governing body of the UNFCCG), with the AFB functioning as the operating entity of the Fund and with a developing country majority membership, including special seats for least developed countries (LDCs) and small island developing states (SIDS). ${ }^{1}$ The World Bank would serve as the Trustee, with very restricted functions. It thereby reflected many of the positions expressed previously by key negotiators from LDCs and small island countries (Abdullah et al. 2006; Sopoaga et al. 2007).

In the centre of these discussions was the role of the GEF, which was proposed variously by the EU, Japan, Canada and Switzerland as the Fund's managing entity as early as 2006 (UNFCGC 2006). However, many developing countries, especially the LDCs, but also the Alliance of Small Island States (AOSIS), had several reservations based in particular on their previous experiences of projects and governance of the GEF (Tuvalu 2006; Pew Center 2007). Furthermore, the Philippines strongly objected to the influence of the USA in the GEF when it was not a Kyoto Protocol signatory (UNFCGC 2006). According to various UNFCGG delegates, the GEF lobbied during the Bali summit to obtain a strong role in the Fund (ECO 2007). Eventually, the GEF was invited to serve as the secretariat on an interim basis and not as the operating entity of the Fund itself, which left the GEF with a significantly weaker role than in the other funds operated under the Convention.

Reflecting the debate prior to Bali, there seems to have been convergence towards the view that 
the particular niche of the Adaptation Fund should be to fund concrete project activities (albeit not necessarily as an exclusive focus) (UNFGGG 2006). This view was also shared by developed countries, who nevertheless stressed the importance of funding such activities in an integrated manner consistent with national policies. One of the key arguments in favour of the GEF was the perception that only the operation by the same entity would ensure avoiding duplication across funds. The GEF as an entity linked to several Multilateral

Environmental Agreements was also expected to ensure better the consistency of national policies and to avoid 'standalone' approaches. In contrast, the new features of the Fund in the view of developing countries justified that 'the Fund is in a league of its own, and that it is sufficiently different from the other funds to necessitate the creation of a "standalone" governance structure with an entirely new operating body' (Sopoaga et al. 2007). This shows that the key reasons for the developing countries to fight for the independent Fund were more the desire for establishing structures independent of the conventional, donor-driven finance architecture, including based on the argument that adaptation is rather restitution than development aid, than the nature of concrete adaptation as such compared to the need for mainstreaming.

When the AFB started its work in March 2008, the relationship to the GEF was still influenced by these tensions. The AFB made it clear that the Fund is not operating under GEF rules, but had to design its own rules. The challenge was that it was GEF staff that provided draft documents on several issues in their role as the provider of secretariat services. However, since then, a solid working relationship has been established, with the GEF accepting its subordinated role, but nonetheless making available its important endogenous expertise, for example with regard to the review of projects and programmes.

Since these early tensions, as the Fund has become an established and operational institution, its role in the overall climate finance landscape has become far more relevant. Currently, there are three multilateral funds which have adaptation as their key objective. Each of them are supposed to perform different functions:
- The Adaptation Fund, set up under the Kyoto Protocol under the UNFCCG, which is to finance concrete adaptation projects and programmes;

- The Least Developed Countries Fund (LDCF) set up under the UNFCCG and operated by the GEF; its focus is to assist the 48 LDCs in the preparation and implementation of National Adaptation Programmes of Action (NAPAs). Fed by voluntary pledges, the available resources are significantly less than would be required to implement the NAPAs in full;

- The Pilot Program for Climate Resilience (PPCR) within the Climate Investment Funds set up under the World Bank, with the purpose to finance pilot programmes for integrating adaptation into national planning. Currently, it addresses nine countries and two additional regions. The Fund was set up outside the UNFCGC process, but through contributions by donor countries, it has become by far the largest adaptation-related multilateral fund (see Seballos and Kreft; Ayers et al.; Shankland and Chambote; all in this IDS Bulletin).

In terms of political economy, the most relevant aspect today is why the Fund is the one which has received the smallest amount of donor contributions (see Kaloga 2010, for an overview). There are a variety of different reasons:

- The Fund was intended to be funded by a levy on transactions in the CDM and thereby to be independent and self-standing; some developed countries argue that adding voluntary contributions might cause interference with this independence; however, at low carbon prices the CDM levy alone does not generate sufficient resources.

- Most of the donor countries were not happy with the innovative features of the Fund (but had to give in because of the political pressure at COP13 in Bali), so they were hesitant in supporting the Fund early on.

- The Fund utilises a new kind of institutional arrangement, where it was not clear if and when it would prove successful.

- The Fund's focus on separate projects and programmes does not reflect the funding preferences of donor countries which give more priority to climate proofing of investments and mainstreaming of adaptation.

- ODA is usually channelled through developing countries' finance ministries, whereas the 
UNFCGC processes are in the hands of environment ministries, and there is hesitance on the donor side to deal with the unfamiliar pathways on a significant financial scale.

Thus, the fact that the PPCR so far received about ten times the amount of resources that have been given to the Fund reflects the overall preference of many donor countries towards mainstreaming adaptation, rather than funding concrete projects, and also towards the World Bank as a managing body (see Seballos and Kreft, this IDS Bulletin). The establishment of the new Green Climate Fund as agreed in Cancun in 2010 is now a challenge for the future of the Fund (and also the other adaptation-related funds). So far, the scope of this new fund and the relationship to the other existing funds is not clear. However, its establishment will only be justified if it will be much bigger in scope with more available resources. There may be different implications on the role of the Fund, from becoming irrelevant and 'drying out' because of lack of resources to a model of fruitful coexistence (see Harmeling 2009). Developing country representatives such as the former AFB chair Farrukh Iqbal Khan have already argued that the Fund should get a bigger role in the Green Climate Fund as its adaptation window (Doyle 2010).

\section{Political economy of Fund governance:} vulnerable countries and project decisions

An outcome of the power play experienced during the Bali COP of 2007 is the governance structure of the AFB. For the first time in multilateral finance, a governance model was agreed which gives developing countries a small majority. This majority, however, does not mean that developing countries can overrule developed countries, since a consensus is required and if not reached, a twothirds majority takes the decision. According to their mandate, the AFB members are representing specific country group constituencies (one of the five UN regions, Annex I, non-Annex I, LDCs, SIDS), rather than their origin countries' positions. Reflecting the first three years of the Fund's work, the AFB has proven that it strives for consensus based on substantive and mostly objective discussions² (see also Doyle 2010). Nevertheless, there are issues where the specific constituencies' interests may affect the members' positioning. Two issues will be looked at more closely here: the prioritisation of particularly vulnerable countries and the approval of projects and programmes.

\subsection{Adaptation Fund prioritisation of vulnerable countries}

According to the Fund mandate 'developing country Parties to the Kyoto Protocol that are particularly vulnerable to the adverse effects of climate change' are eligible to receive funding (UNFCGC 2007). The decision referred to the definition of vulnerability contained in the Convention which is so broad that almost every developing country can count itself 'particularly vulnerable' (see Klein and Möhner, this IDS Bulletin). ${ }^{3}$ With scarce resources available in the Fund, it appeared necessary early on to identify those particularly vulnerable countries, or a further detailed prioritisation, since there are 149 developing country Parties to the Kyoto Protocol. When the Bali Action Plan concluded with a specific prioritisation of country groups, namely LDCs, SIDS and further taking into account African countries prone to drought, floods and desertification, there was the opportunity to bring down the number of countries to around 100 (see also Huq and Ayers 2007). However, in the debate during 2008 and 2009, there was opposition to use of the Bali Action Plan definition. This came especially from those countries/regions strongly represented in the AFB and in UNFCGC negotiations as a whole, but which are not included in this definition of 'particularly vulnerable', in particular Latin American and Caribbean countries, but also countries from Central Asia, all of whom are facing severe threats from climate change. In addition, Qatar, formally representing Asia in the AFB but with a Middle East OPEG country perspective, also worked towards the UNFGCG definition in the 2008 AFB meetings.

Given the lack of agreement, the AFB finally agreed to stick to the UNFCGC definition, which is so broad that every developing country can find itself covered. The AFB debated throughout 2009 and 2010 a number of approaches on how to prioritise funding among the eligible countries (such as per-country caps, regional allocations, etc., see AFB 2010a). However, no agreement has yet been reached, and obviously the specific interests of the constituencies represented in the $\mathrm{AFB}$ are one central reason for this.

To some extent, until a decision on the funding priorities is taken, the Fund works on a firstcome, first-served basis, as long as the submitted projects meet the required criteria. This lack of prioritisation is likely also to be a reason for 
some donor countries' willingness to give any (or more) money to the Fund.

\subsection{Adaptation Fund projects and programme approval} Since its tenth meeting in June 2010, the AFB is able to consider concrete adaptation project and programme proposals. One aspect which needs to be critically examined from a political economy perspective, is whether decisions on projects and programmes give any indication that AFB members ground their decisions on the interests of the constituencies or countries they represent rather than on the objective performance of the project proposals with regard to the criteria agreed by the AFB.

Assessing projects and programmes submitted to the AFB is the key task of the Projects and Programmes Review Committee (PPRG) established under the AFB, based on technical screenings prepared by the AFB Secretariat. ${ }^{4}$ One challenge here is that the PPRC considers the projects in closed meetings and so far has not provided information why certain projects and programmes were approved or not approved to the public, only to the implementing entities. It is argued by the AFB that this is to ensure confidentiality, but it also constitutes a lack of transparency.

One important safeguard for more objective decisions is that a member of the PPRC has to exit the room when a project submitted by its country is considered, and they are formally involved in recommendations on that specific project. However, theoretically, there might be power plays behind the scenes to ensure that an AFB member 'brings home' resources from the Fund. Given the lack of publicly available information, it is difficult to assess whether the approved projects and programmes are really judged better than those not accepted.

Up to March $2011,{ }^{5}$ the percentage of positive responses by the AFB of total projects submitted is 60 per cent ( 15 out of 25 submitted). However, of those submitted by countries with representation on the AFB, the percentage is 77 per cent ( 7 from 9 ), while for those without representation the proposal success rate is only 50 per cent. ${ }^{6}$

While every developing country can work through the project submission templates and criteria, it is of course the AFB members who have the most insight into the rules of the AFB since they have participated in their design, which is a comparative advantage. However, concluding that this is a result of their stronger powers as members of the AFB is perhaps not appropriate. The quantitative basis for this analysis is not significant to draw conclusions, as the reasons for the project endorsements and rejections have not been made public so far. At its thirteenth meeting, the AFB decided to change this practice and from now on will provide information on the key weaknesses of a project which led to non-approval, or, in the case of project concepts, which should be improved in the preparation of the final full project submission. ${ }^{7}$ This will counter potential comparative advantages of AFB representation.

\section{Political economy at national level: National Implementing Entity selection and stakeholder inclusion}

In particular through the opportunity of direct access, the Fund intends to allow developing countries to take up more ownership and responsibility. The way this responsibility will be shared within developing countries, between governments and other relevant stakeholders, will also be an important benchmark to judge the implications of the Fund on the political economy of adaptation funding. One starting point is to look at the direct access model itself. Here one has to recognise that although the Fund is the first multilateral climate fund which allows for direct access, thereby avoiding the need for intermediate implementing agencies, it is not new to multilateral development finance. One example is the Global Fund to Fight AIDS, Tuberculosis and Malaria. When the AFB designed its direct access approach, starting in 2008 , it looked at this fund in particular and also consulted with its staff and experts (AFB 2008).

The solution developed by the AFB, however, is very different from the one of the Global Fund. It can be described as a 'government-run model'. As well as multilateral implementing entities (MIEs) familiar to other global funds, national governments of developing countries are able to nominate a national implementing entity (NIE) to the AFB. The NIEs are responsible for organising the project level monitoring, reporting and evaluation, including the final evaluation. The national government is also 
responsible for endorsing which project to submit to the AFB through the NIE in the case of direct access. Thus, the key steps are fully in the hands of the governments.

In contrast, the Global Fund model is more complex, but also much more inclusive and can be seen as a 'partnership model'. The actor taking the key decisions is the so-called 'country coordinating mechanism', which usually includes representatives from the government, multi- and bilateral development partners, NGOs, affected communities, academic institutions, private sector or faith-based organisations. ${ }^{8}$ Further institutional elements at the country level are the so-called 'principal recipients' (PRs). They basically perform the fiduciary management function which the NIEs perform in the case of the Adaptation Fund. The third element is the socalled 'local fund agent', private companies which independently evaluate the work of the PRs.

While there may be different reasons for the choice of the AFB on the particular model, including expecting significantly lower funds to be disbursed than in the Global Fund, this choice reflects the government's particular perception of its own role in the UNFCGC process. Since the Climate Change Convention and the Kyoto Protocol are agreements among governments, involvement of other stakeholders is more seen as an issue of national sovereignty and nothing to be prescribed at the global level. The Global Fund in contrast was designed as a multi-level partnership. The consequence is that in the case of the Fund, governments do not necessarily have to include non-governmental stakeholders in their decisions. This can be relevant both with regard to the choice of the implementing entities as well as the design of projects and programmes.

There is limited empirical evidence to analyse these processes, as governments do not have to provide information on the process which led to the decision for a specific MIE or NIE. Regarding direct access, only three NIEs have been accredited so far, with two out of 25 projects submitted by an NIE (see Table 1). The three accredited NIEs to date are very different from each other, suggesting that there is not one particular model to follow (see Brown and Schalatek 2010, for an overview of different features). As of December 2010, there are a number of additional applications for NIEs under review, from a range of types of government department, all selected with limited consultation outside the government (AFB 2010b). By contrast, the decision in Senegal to appoint the Centre de Suivi Ecologique as the NIE was taken, based on consultations with non-governmental stakeholders.

The identification, selection, design and implementation of projects submitted to the AFB for funding is another important component to assess the current power relationships between governments and their citizens (organised or not) in the context of the AFB. While the AFB has the strategic priority that 'when designing adaptation projects and programmes, developing country governments shall give special attention to the particular needs of the most vulnerable communities', it has not yet prescribed that these communities or organisations representing them must have a specific role in the project cycle. So far, it is up to each government whether and how it includes other stakeholders in the project process. In the project applications, project proponents are requested to describe the consultative process, as well as how they address the benefits for vulnerable communities (AFB 2010c). But more explicit guidance is not given by the AFB on what stakeholder consultations accurately means, whether the consultation should be undertaken prior to or during the project concept or more as an ongoing process during its implementation, nor which level of inclusion is expected by the Fund for the funding approval.

There are only two out of the 24 projects submitted so far which give non-governmental stakeholders - civil society, private sector and others - an explicit role in the project execution, as executing entities: the Senegalese direct access project, and the project from Uganda submitted through the World Food Programme (see Germanwatch 2010). The way that the consultative process is carried out and described varies significantly, as can be seen in Table 2. For this, the authors grouped the descriptions of the consultative processes in all 24 projects in four categories. Those proposals containing an 'annotated list of stakeholder consultation' is considered the most favourable and in this context, refers to examples which list specific stakeholders that have been consulted with their anticipated role or their specific contribution to 


\begin{tabular}{|c|c|c|c|}
\hline \multirow{2}{*}{$\begin{array}{l}\text { Stakeholder } \\
\text { consultation process* }\end{array}$} & \multicolumn{3}{|c|}{ Countries } \\
\hline & No of countries & Project concepts & Full projects \\
\hline No list of stakeholders & 7 & $\begin{array}{l}\text { Georgia, India, Madagascar, } \\
\text { Mauritania, Uganda, Uruguay }\end{array}$ & Honduras \\
\hline $\begin{array}{l}\text { List of stakeholders who } \\
\text { will be consulted }\end{array}$ & 7 & $\begin{array}{l}\text { Cook Islands, Fiji, Maldives, Mongolia, } \\
\text { Nive, Papua New Guinea }\end{array}$ & Turkmenistan \\
\hline $\begin{array}{l}\text { Simple list of stakeholders } \\
\text { already consulted }\end{array}$ & 6 & El Salvador, Guatemala & $\begin{array}{l}\text { Eritrea, Mauritius, Senegal, } \\
\text { Solomon Islands }\end{array}$ \\
\hline $\begin{array}{l}\text { Annotated list of } \\
\text { stakeholder consultation }\end{array}$ & 5 & & $\begin{array}{l}\text { Ecuador, Egypt, Nicaragua, } \\
\text { Pakistan, Tanzania }\end{array}$ \\
\hline \multicolumn{4}{|c|}{$\begin{array}{l}\text { *All information about the above-mentioned proposals are available at: http://adaptation-fund.org/ } \\
\text { projectprogrammeproposals or http://adaptation-fund.org/fundedprojects } \\
\text { Source Own compilation based on project proposals to the AFB. }\end{array}$} \\
\hline
\end{tabular}

the preparation of the project. Most of the projects belong to the lower categories with weaker description of the consultative process.

Table 2 further shows which of the projects and programmes have been accepted by the AFB as full projects. There appears to be no consistent relationship between the approval of concepts and full projects with the quality of the consultative process. This is, to some extent, not surprising, since the consultative process is only one of several criteria to judge the projects. However, it supports the assertion that the Fund has not played an active role to date in strengthening the inclusion of non-governmental stakeholders.

\section{Conclusions}

This article has investigated different aspects of the political economy of the Adaptation Fund. It was shown that the origin of the Fund itself was subject to certain power plays on the international institutional level, in particular with regard to the GEF. In the end, the decision in Bali in 2007 was a relative success for vulnerable developing countries such as LDCs and SIDS. The agreement marked a turn-away from the 'business-as-usual' approach favoured by developed countries to just let the GEF do this job. Standing firm behind their demands, highlighting the special nature of adaptation and their particular vulnerability, these countries ensured that the Fund could pursue and pilot new modalities of climate finance. Today the more decisive debate is about the Fund in the overall climate finance arena. The PPGR has emerged as the fund which received most of the donor money, favouring donor interests and preferences for multilateral funding. With the decision to establish the new Green Climate Fund achieved in Cancun, the role of the Fund in the future is more uncertain. However, we argue that the more successful the Fund becomes in funding good adaptation projects and programmes and in establishing direct access, the more likely it is that it will have an important role to play.

With regard to the AFB, the particular interests of its members or the constituencies they represent have become apparent in the debate about prioritising countries that are particularly vulnerable. The decision-making power of some AFB members representing countries which do not belong to the group of 'particularly vulnerable countries' names in the Bali Action Plan (LDCs, SIDS and countries in Africa prone to droughts, floods and desertification), has hindered agreement on this prioritisation. The AFB still struggles with this issue despite more than two years of debate. The special role of the AFB members could in theory also impact on the decisions on funding of projects and programmes, as projects submitted by countries with AFB members have performed significantly better than other projects. However, there is no evidence to assume that this is due to interferences caused by the members' specific powers. It is rather likely that they have a 
comparative advantage because they have followed the development of project modalities and the overall rationale of the Fund much more closely. Nevertheless, there is the need to become more transparent on the funding decisions.

On the national level within developing countries, a key question is the relationship between governments and non-governmental stakeholders of different kinds, be they NGOs, community-based organisations or from the private sector. The way the Fund has designed the direct access approach does not set particular incentives to include multiple stakeholders in the whole process of identifying national implementing entities and projects and programmes, as well as their implementation. This is in contrast to, for example, the direct access model of the Global Fund to Fight AIDS, Tuberculosis and Malaria. Furthermore, the way

\section{Notes}

* The authors have been following the development of the Adaptation Fund since the first meeting of the AFB in March 2008. This article is based significantly on the personal observations of the authors, who attended all AFB meetings until the recent climate summit in Cancun.

1 Funds previously established under the UNFCGC only operate under the guidance of the COP. The issue of 'guidance vs authority' has been subject to controversial debates also at COP15 in Copenhagen and in the run-up to COP16; see also Müller (2009). Granting the new AFB the role of an operating entity of the Fund was a new institutional approach, since usually the GEF is perceived as the operating entity of the financial mechanism of the UNFCGC, and since Art. 11.2 of the UNFGCG only allows existing institutions to be an operating entity of the whole financial mechanism.

2 The two-thirds in order to be a quorum necessitates the collaboration of developed and developing countries, since none of them can alone provide the required two-thirds majority. that governments include multiple stakeholders in the identification and design of projects varies significantly and lacks better guidance from the AFB. It remains dependent on a national government whether and how it wants to include other stakeholders, which constitutes a weakness of the current procedures.

Overall, the Adaptation Fund has matured significantly, but it faces a number of challenges of which some are related to aspects of political economy on levels where the AFB can have a direct influence, such as through greater transparency on the project funding decisions or guidance for stakeholder inclusion. However, the successful development of the Fund and its role in the wider climate finance architecture will also depend on how governments work to ensure the Fund delivers effective and accountable adaptation interventions in the future.

3 Decision 28/CMP.1: 'Recognising that low-lying and other small island countries, countries with low-lying coastal, arid and semi-arid areas or areas liable to floods, drought and desertification, and developing countries with fragile mountainous ecosystems are particularly vulnerable to the adverse effects of climate change' (see UNFCGC 2005).

4 The PPRC comprises half of the AFB members and alternates. The AFB Secretariat relies substantially on the capacity of GEF staff not formally assigned to the AFB Secretariat to prepare the technical screenings.

5 As from after the twelfth AFB meeting, December 2010.

6 Own calculations based on Germanwatch (2011).

7 The final report of the thirteenth AFB meeting was not available publicly at the time of finalising this article, but the authors were present when the AFB members took this decision which only needs formalisation.

8 See www.theglobalfund.org/en/structures/ ?lang $=$ en for a description of the basic structure. 


\section{References}

Abdullah, A.; Jallow, B.P. and Reazuddin, M. (2006) Operationalising the Kyoto Protocol's Adaptation Fund: A New Proposal, http://pubs.iied.org/ 11061IIED.html (accessed 27 January 2011) AFB (2010a) Initial Funding Priorities, AFB/B.12/5. 15 November, Washington DC: Adaptation Fund Board, www.adaptationfund.org/system/ files/AFB.B.12.5.Initial\%20 Funding\%20Priorities.pdf (accessed 27 January 2011)

AFB (2010b) Report of the Fourth Meeting of the Accreditation Panel, AFB/B.12/4, 10 December, Washington DC: Adaptation Fund Board, www.adaptation-fund.org/system/files/Final\% 20AP\%20report_0.pdf (accessed 27 January 2011)

AFB (2010c) Request for Project/Programme Funding from Adaptation Fund (Form), Washington DC: Adaptation Fund Board, www.adaptationfund.org/system/files/file/AF_Request\%20for \%20Project_Programme\%20Funding.doc (accessed 27 January 2011)

AFB (2008) Report of the 3rd Meeting of the Adaptation Fund Board, AFB/B.3/15, 24 September, Washington DC: Adaptation Fund Board, http://adaptation-fund.org/system/ files/AFB.B.3.15_Report_of_Third_AFB_ Meeting.doc (accessed $2 \overline{7}$ January 2011$)$

Brown, J. and Schalatek, L. (2010) Direct Access to the Adaptation Fund: Realising the Potential of National Implementing Entities, www.boell.org/ downloads/ThirdCF_Brief_AFandDirectAcces s _Boell-ODI.pdf (accessed 27 January 2011)

Chandani, A.; Harmeling, S. and Kaloga, A. (2009) The Adaptation Fund - A Model for the Future?', IIED Briefing, August, www.germanwatch.org/klima/adbr09.pdf (accessed 27 January 2011)

Doyle, A. (2010) Tiny U.N. Climate Fund could take Bigger Role, Chair, Reuters, 17 November, www.reuters.com/article/idUSTRE6AG28Y20 101117?utm_source $=$ feedburner\&utm medium $=$ feed\&utm_campaign $=$ Feed $\% 3 \mathrm{~A}+$ reuters $\% 2$ Fenvironment $+\% 28 \mathrm{News}+\% 2 \mathrm{~F}+$ US+\%2F+Environment $\% 29$ (accessed 27 January 2011)

ECO (2007) 'AF or GEF? Keep Your Eye on the Ball!', ECO NGO newsletter COP13, 6 December, www.climatenetwork.org/sites/default/files/ ECOcop13n05.pdf (accessed 27 January 2011)

Germanwatch (2010) Germanwatch Adaptation Fund Project Tracker, www.germanwatch.org/ klima/afpt.htm (accessed 27 January 2011)
Harmeling, S. (2009) 'The Adaptation Fund in the Debate on the Post-2012 Financial Architecture', Germanwatch Briefing Paper, December, www.germanwatch.org/klima/ afpost2012.htm (accessed 27 January 2011)

Huq, S. and Ayers, J. (2007) Critical List: The 100 Nations most Vulnerable to Climate Change, IIED, http://pubs.iied.org/17022IIED.html (accessed 27 January 2011)

Kaloga, A. (2010) 'International Adaptation Funding: A Drop in the Ocean', in Adaptation Fund NGO newsletter, 1/2010, www.germanwatch.org/klima/afnl-nol.pdf (accessed 27 January 2011)

Müller, B. (2009) Under the Authority of the COP, Oxford Energy and Environment Comment, November, www.oxfordenergy.org/pdfs/ comment_02_10_09.pdf (accessed 27 January 2011)

Müller, B. (2006) Nairobi 2006. Trust and the Future of Adaptation Funding, Oxford Institute for Energy Studies, December, www.oxfordenergy.org/ pdfs/EV38.pdf (accessed 27 January 2011)

Pew Center on Global Climate Change (2007) Thirteenth Session of the Conference of the Parties to the UN Framework Convention on Climate Change and Third Session of the Meeting of the Parties to the Kyoto Protocol, 3-15 December, Bali, Indonesia, www.pewclimate.org/docUploads/Pew\%20 Center_COP\%2013\%20Summary.pdf (accessed 27 January 2011)

Sopoaga, E.; Greyling, L.; Lesolle, D.; Massawa, E. and Miguez, J. (2007) On the Road to Bali: Operationalising the Kyoto Protocol Adaptation Fund, International Institute for Environment and Development, http://pubs.iied.org/ 17018IIED.html (accessed 27 January 2011)

Tuvalu (on behalf of AOSIS) (2006) Views on Specific, Policies, Programmes, Priorities and Eligibility Criteria of the Adaptation Fund, submission by Tuvalu on Behalf of the AOSIS, in FCGC/SBI/2006/MISC.7, p.21f., http://unfccc.int/resource/docs/2006/sbi/eng/ misc07.pdf (accessed 27 January 2011)

UNFCGC (2007) Adaptation Fund. Decision 1/CMP.3, http://unfccc.int/resource/docs/ 2007/cmp3/eng/09a01.pdf\#page =3 (accessed 27 January 2011)

UNFCCG (2006) Views from Parties and Relevant International Organizations on Possible Arrangements for the Management of the Adaptation Fund, Bonn, http://unfccc.int/resource/docs/ 2006/sbi/eng/misc07.pdf (accessed 27 January 2011) 
UNFCGC (2005) Decision 28/CMP.1, UNFGCG

Secretariat, Bonn, http://unfccc.int/resource/ docs/2005/cmpl/eng/08a04.pdf\#page $=3$

(accessed 27 January 2011) 